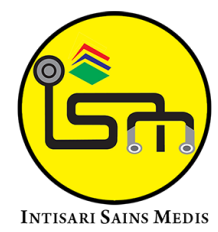

Published by Intisari Sains Medis

\section{Inflammation after corneoscleral rupture and traumatic cataract due to blunt trauma in a child: a case report}

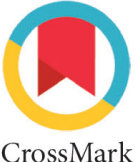

${ }^{1}$ General Practitioners, Jakarta Eye Center Hospitals and Clinics, Jakarta, Indonesia;

2Division of Cornea, Cataract and Refractive Surgery, Jakarta Eye Center Hospitals and Clinics, Jakarta, Indonesia;

\section{*Corresponding author:}

Clara Verlina Suhardi;

General Practitioners, Jakarta Eye Center Hospitals and Clinics, Jakarta, Indonesia;

claraverlina@ymail.com

Received: 2021-06-22

Accepted: 2021-08-18

Published: 2021-05-31

\author{
Clara Verlina Suhardi i ${ }^{*}$, Graecia Bungaran', Nashrul Ihsan²
}

\title{
ABSTRACT
}

Background: Ocular trauma is the most common cause of acquired monocular blindness in children. It is because of the inflammation following corneoscleral rupture and traumatic cataracts due to blunt trauma. This case study aims to evaluate the corneoscleral rupture and traumatic cataracts due to blunt trauma in a child.

Case Presentation: We present a 5-year-old male who sustained blunt trauma to his right eye. He presented with blurry vision, mild pain and watering from the affected eye. His examination revealed visual acuity of $6 / 60$ in the right eye (RE), corneal laceration extending from 3 o'clock towards 11 o'clock with possible extension to the sclera, and cortical lens matter in the anterior chamber. The patient underwent globe rupture repair under general anesthesia immediately. Postoperative day one revealed $2 \mathrm{~mm}$ hypopyon thick inflammation cells and fibrin. He was on topical steroids and topical antibiotics. The fourth postoperative day showed reduced inflammation, wound sutures in place and absence of hypopyon, thick membranous in the pupil. The patient is then referred to the Pediatric Ophthalmology department for a follow-up operation of clearing lens particle remnants to reduce inflammation and IOL insertion. Conclusion: Management of the injury and traumatic cataract is crucial to prevent vision loss and amblyopia, to maintain binocularity, prevent strabismus or even phthisis bulbi. Along with early management, routine follow-up examination for prevention of other unwanted complications is advised.

Keywords: Blunt Trauma, Case Report, Child, Cornealscleral Rupture, Traumatic Cataract.

Cite This Article: Suhardi, C.V., Bungaran, G., Ihsan, N. 2021. Inflammation after corneoscleral rupture and traumatic cataract due to blunt trauma in a child: a case report. Intisari Sains Medis 12(2): 617-620. D0I: 10.15562/ ism.v12i2.1068

\section{INTRODUCTION}

Ocular trauma is the most common cause of acquired monocular blindness in children. Globally, around 3.3-5.7 million children under 15 years of age suffer from ocular trauma every year with pediatric ocular trauma being more prevalent in males. ${ }^{1}$ There are still very limited data regarding pediatric ocular trauma in Indonesia; however, reports from the United States estimated OGI to occur at a rate of 2-3.8/100,000. Visual prognosis of OGI in children is worse than adults due to the severe nature of injuries, amblyopia, traumatic cataract, and infectious endophthalmitis due to delayed presentation. ${ }^{2,3}$

Blindness or impaired vision carries heavy psychological, social, and economic burdens, significantly decreasing quality of life. ${ }^{4}$ A thorough understanding of the epidemiology, diagnosis, management, and the prognosis is critical to preventing vision loss early in life after injury. ${ }^{5}$

Inflammation is the immune system's reaction to damaging stimuli like pathogens, damaged cells, poisonous substances, or irradiation, and it works by eliminating injurious stimuli and commencing the healing process. ${ }^{6,7}$ Typically, cellular and molecular activities and interactions efficiently limit impending harm or infection during acute inflammatory responses. The restoration of tissue homeostasis and the resolution of acute inflammation are both aided by this mitigation process. On the other hand, uncontrolled acute inflammation can develop chronic, leading to a range of chronic inflammatory disorders. ${ }^{8}$
Inflammation can also occur as a result of blunt trauma, according to a prior study. ${ }^{9}$

Based on those mentioned above, this case study aims to evaluate the current management of inflammation after corneoscleral rupture and traumatic cataracts due to blunt trauma in a child.

\section{CASE REPORT}

A previously healthy 5-year-old male child was admitted to the outpatient department after falling off his bike and his right eye hitting the handlebar one day prior to arrival. He reported no loss of consciousness, nausea or vomiting after the incident. The patient did not have any prior ocular injuries, history of ocular disease, or prior ocular surgeries. The patient reported that he does not wear glasses. He complained of blurry vision, 
mild pain and watering from the affected eye.

On examination, the patient had visual acuity of $6 / 60$ in the right eye (RE) and $0,7 \mathrm{~F}$ in the left eye (LE). His RE showed subconjunctival hemorrhage on slitlamp examination, a corneal laceration extending from 3 o'clock towards 11 oclock with possible extension to the sclera, and cortical lens matter in the anterior chamber (Figure 1). The posterior segment could not be examined. The patient was then

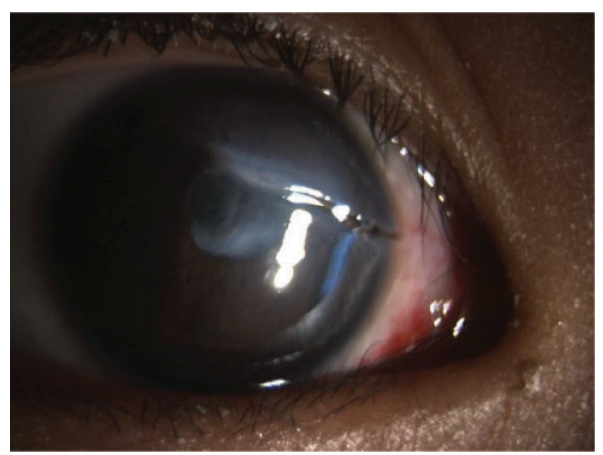

Figure 1. Slit-lamp examination of the right eye showing corneal laceration.
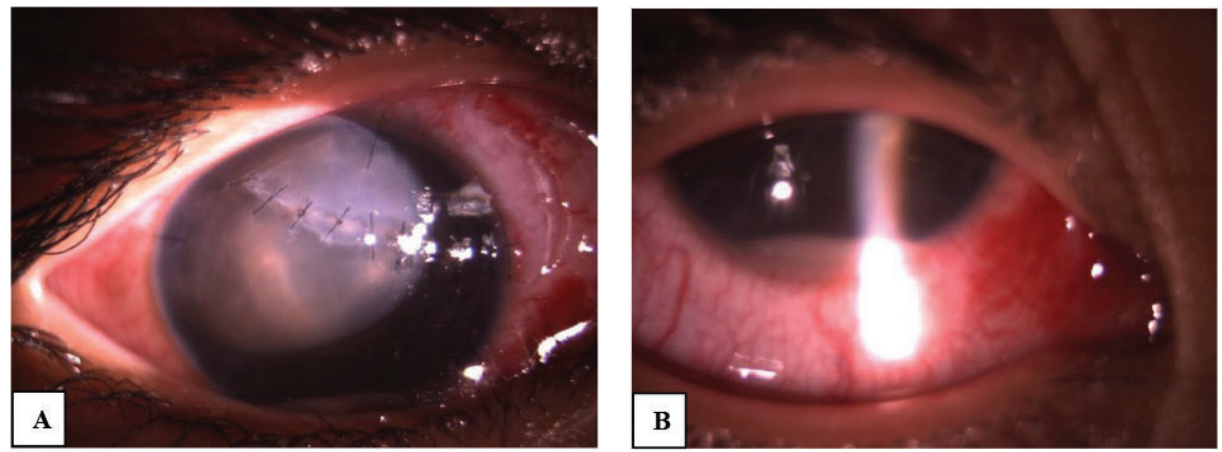

Figure 2. (A) Day one post-surgery showed sutures in place; (b) hypopyon, cells and fibrin in the anterior chamber.
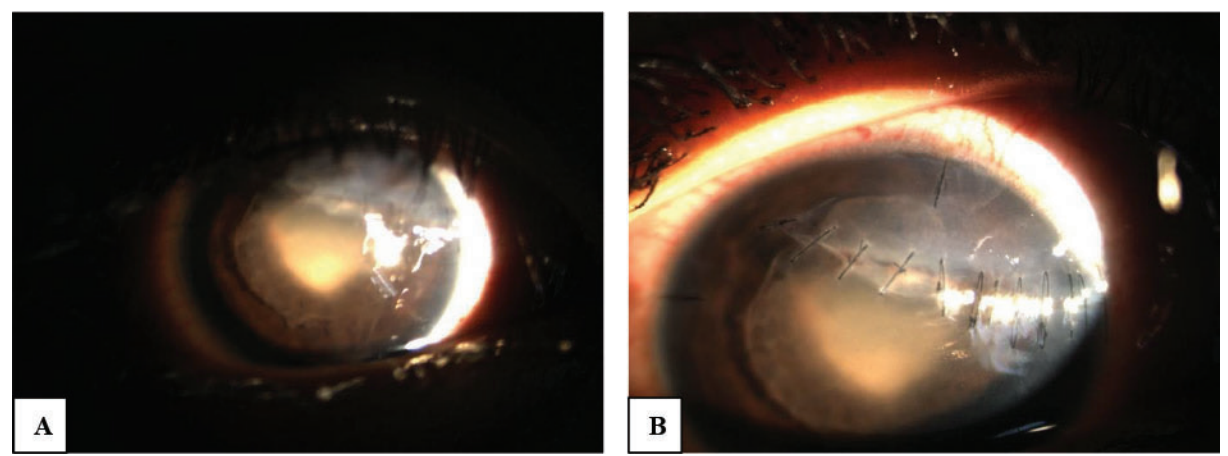

Figure 3. (A) Day 4 post-surgery showed wound sutures in place; (B) Absence of hypopyon, cells, and fibrin.

prepared for globe rupture repair under general anesthesia (GA) immediately. Chest X-Ray and Laboratory tests included a full blood count, liver function tests, INR, prothrombin time, partial thromboplastin time, kidney function tests were assessed and all were within normal. These tests were done for preoperative preparation in general anesthesia.

On the initial surgery, 12 stitches were done with nylon 10.0 for the laceration from the cornea extending to the limbus. In the surgery, lens particles seen on the $\mathrm{COA}$ were removed with Irrigation and Aspiration tip, without intraocular lens implantation. The posterior capsule lens ruptured due to trauma and vitreous contents were found in the COA, which hindered the cataract extraction process. This initial operation was done solely to close globe rupture to maintain $\mathrm{RE}$ integrity and prevent further infection and unwanted complications. At surgery, the vitreous was found in the anterior chamber.

The first postoperative visit revealed corneal edema with sutures in place, 2 
RE. A separate category of intraocular foreign body (IOFB) is penetrating injuries in which foreign bodies remain inside the globe. ${ }^{5,14}$

Duringtheinitialassessment, a complete history should focus on the etiology of the trauma. The initial examination evaluates the patient's visual acuity (VA). A thorough slit lamp examination should be performed to assess the conjunctiva, sclera, cornea, anterior chamber, visible foreign body or lacerations, and the pupil should be examined for shape and reactivity. Avoid applying pressure to the globe, including eversion of the lids and tonometry. Intraocular foreign body (IOFB) is suspected of the explosion, gunshot wound, or sharp object entering the eye; therefore, appropriate imaging should be done. The primary imaging modalities used when needed are computerized tomography (CT) and B-scan ultrasonography; magnetic resonance imaging (MRI) is only used to detect non-metallic IOFB, if metallic IOFB is suspected, then MRI is contraindicated. ${ }^{5}$

The affected eye should be covered using a protective device. In awake and alert patients, antiemetics and analgesics should reduce stressors that may increase intraocular pressure. A tetanus shot should be given if recent immunization was uncertain. ${ }^{15}$ Surgical management by an ophthalmologist should be done as soon as the patient can safely undergo surgery. Any delay in surgical intervention could lead to worse outcomes and increase the risk of postoperative endophthalmitis. The main goals of surgery are to close primary wounds, reposition of prolapsed ocular contents or debride if extruded for more than 24 hours, IOFB removal, and treat or prevent complications from preserving VA. ${ }^{5}$ Hence in this patient repair surgery was done CITO (on the day of the trauma) in hopes of a better prognosis.

In traumatic pediatric cataracts, if the anterior capsule is significantly disrupted and free-floating lens matter in the anterior chamber is observed, the surgeon may be justified for primary cataract extraction with or without IOL implantation. Increased risk for infection, raised IOP, and retinal detachment was observed after primary IOL implantation; hence secondary IOL implantation is recommended. ${ }^{16}$ Repair of the patient's RE was done under general anesthesia (GA), the corneal wound was sutured, traumatic cataract was removed without IOL implantation because of the nature of the inflammation occurring in the RE. Also, vitreous was found in the anterior chamber, which gave other difficulties. Limbal sutures were placed, subconjunctival antibiotics and steroids were given and the patient was left aphakic. Postoperative consultations were done to monitor the $\mathrm{RE}$ to reduce inflammation with a further thorough evaluation of the posterior segment of the RE. During the first day of postoperative, medication administration to the operated eye was not given; poor medication compliance plays a factor in severe inflammation found during day one postoperative follow-up. The presence of hypopyon and inflammation cells in the RE can also be caused by an infection process that is still occurring. Observation post-operation found unusually severe inflammation reaction halting plans for a secondary operation. Improved medication administration on the RE resulted in partial inflammation resolution on the fourth day of postoperative followup.

The Area of injury is classified according to the Ocular Trauma Classification Group into three anatomical zones. Zone I includes the cornea and limbus, zone II is corneoscleral limbus to a point $5 \mathrm{~mm}$ posterior into the sclera, and zone III is wound involvement posterior to the anterior $5 \mathrm{~mm}$ of the sclera. ${ }^{17,18}$

Ocular Trauma Score (OTS) use as a reliable prognostic tool to predict the visual outcomes in pediatrics after ocular trauma with traumatic cataracts. ${ }^{19,20}$ The OTS scoring system includes visual acuity at presentation and the extent of ocular trauma, presence or absence of globe rupture, endophthalmitis, retinal detachment, and relative afferent pupillary defect (RAPD). A higher score is associated with a better prognosis. ${ }^{21}$

\section{CONCLUSION}

Management of the injury and traumatic cataract is crucial to prevent vision loss and amblyopia, to maintain binocularity, prevent strabismus or even phthisis bulbi. Along with early management, routine follow-up examination for prevention of other unwanted complications is advised.

\section{CONFLICT OF INTEREST}

We declare that there was no conflict of interest in this case report.

\section{ETHICS CONSIDERATION}

This case study has following the publication ethics guidelines based on COPE and ICMJE protocol prior to the study being published.

\section{FUNDING}

Not applicable.

\section{AUTHORS CONTRIBUTION}

$\mathrm{CV}$ and GB wrote the case report and reviewed the article. NI managed the child in the outpatient department, the surgery operator, and reviewed the manuscript with few changes. All authors read and approved the final manuscript.

\section{REFERENCES}

1. Kumar K, Figurasin R, Kumar S, Waseem M. An Uncommon Meridional Globe Rupture due to Blunt Eye Trauma. Case Rep Emerg Med. 2018;2018:1808509.

2. Gul GA, Raza A. Visual Outcome of Open Globe Injuries in Paediatric Patients. 2017;21(3):226228.

3. El-Sebaity DM, Soliman W, Soliman AM, Fathalla AM. Pediatric eye injuries in upper Egypt. Clin Ophthalmol. 2011;5:1417-1423.

4. Abbott J, Shah P. The epidemiology and etiology of pediatric ocular trauma. Surv Ophthalmol. 2013;58(5):476-485.

5. Li X, Zarbin MA, Bhagat N. Pediatric open globe injury: A review of the literature. J Emerg Trauma Shock. 2015;8(4):216-223.

6. Medzhitov R. Inflammation 2010: new adventures of an old flame. Cell. 2010;140(6):771-776.

7. Ferrero-Miliani L, Nielsen $\mathrm{OH}$, Andersen PS, Girardin SE. Chronic inflammation: importance of NOD2 and NALP3 in interleukin-1beta generation. Clin Exp Immunol. 2007;147(2):227-235.

8. Zhou Y, Hong Y, Huang H. Triptolide Attenuates Inflammatory Response in Membranous Glomerulo-Nephritis Rat via Downregulation of NF- $\kappa$ B Signaling Pathway. Kidney Blood Press Res. 2016;41(6):901-910.

9. Giannoudis PV, Smith RM, Banks RE, Windsor AC, Dickson RA, Guillou PJ. Stimulation of inflammatory markers after blunt trauma. Br J Surg. 1998;85(7):986-990.

10. Qayum S, Anjum R, Rather S. Epidemiological profile of pediatric ocular trauma in a tertiary 
hospital of northern India. Chin J Traumatol. 2018;21(2):100-103.

11. Brophy M, Sinclair SA, Hostetler SG, Xiang H. Pediatric eye injury-related hospitalizations in the United States. Pediatrics. 2006;117(6):e1263-e1271.

12. Liu X, Liu Z, Liu Y, Zhao L, Xu S, Su G, et al. Determination of visual prognosis in children with open globe injuries. Eye (Lond). 2014;28(7):852-6.

13. Bunting $H$, Stephens $D$, Mireskandari K. Prediction of visual outcomes after open globe injury in children: a 17-year Canadian experience. J AAPOS. 2013;17(1):43-48.

14. Schörkhuber MM, Wackernagel W, Riedl R, Schneider MR, Wedrich A. Ocular trauma scores in paediatric open globe injuries. Br J Ophthalmol. 2014;98(5):664-668.
15. Ritson JE, Welch J. The management of open globe eye injuries: a discussion of the classification, diagnosis and management of open globe eye injuries. J R Nav Med Serv. 2013;99(3):127-130.

16. Sen P, Shah C, Sen A, Jain E, Mohan A. Primary versus secondary intraocular lens implantation in traumatic cataract after open-globe injury in pediatric patients. J Cataract Refract Surg. 2018;44(12):1446-1453.

17. Pieramici DJ, Sternberg P Jr, Aaberg TM Sr, Bridges WZ Jr, Capone A Jr, Cardillo JA, et al. A system for classifying mechanical injuries of the eye (globe). The Ocular Trauma Classification Group. Am J Ophthalmol. 1997;123(6):820-31.

18. Acar U, Tok OY, Acar DE, Burcu A, Ornek F. A new ocular trauma score in pediatric penetrating eye injuries. Eye (Lond). 2011;25(3):370-374.
19. Shah MA, Shah SM, Applewar A, Patel C, Patel K. Ocular Trauma Score as a predictor of final visual outcomes in traumatic cataract cases in pediatric patients. J Cataract Refract Surg. 2012;38(6):959-965.

20. Zhu L, Wu Z, Dong F, Feng J, Lou D, Du C, et al. Two kinds of ocular trauma score for paediatric traumatic cataract in penetrating eye injuries. Injury. 2015;46(9):1828-33.

21. Kuhn F, Maisiak R, Mann L, Mester V, Morris $\mathrm{R}$, Witherspoon CD. The Ocular Trauma Score (OTS). Ophthalmol Clin North Am. 2002;15(2):163-vi.

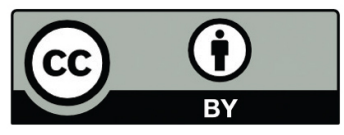

This work is licensed under a Creative Commons Attribution 